\title{
Gastric Atrophy, Intestinal Metaplasia in Helicobacter pylori Gastritis: Prevalence and Predictors Factors
}

\section{S. Adadi' , B. Bennani' ${ }^{2}$, M. Elabkari' ${ }^{1}$, A. Ibrahimi ${ }^{1}$, S. Alaoui ${ }^{2}$, M. Elkhadir $^{2}$, T. Harmouch ${ }^{3}$, M. Mahmoud ${ }^{4}$, C. Nejjari'5, D. Benajah'1}

${ }^{1}$ Service of Hepatology and Gastroenterology, Hassan II University Hospital of Fez, University Sidi Mohamed Ben Abdellah, Fez, Morocco

${ }^{2}$ Microbiology and Molecular Biology Laboratory, Hassan II University Hospital of Fez, University Sidi Mohamed Ben Abdellah, Fez, Morocco

${ }^{3}$ Service of Pathology, Hassan II University Hospital of Fez, University Sidi Mohamed Ben Abdellah, Fez, Morocco ${ }^{4}$ Service of Biology, Hassan II University Hospital of Fez, University Sidi Mohamed Ben Abdellah, Fez, Morocco

${ }^{5}$ Service of Épidémiology, Hassan II University Hospital of Fez, University Sidi Mohamed Ben Abdellah, Fez, Morocco

Email: safae.adadi@hotmail.fr

How to cite this paper: Adadi, S., Bennani, B., Elabkari, M., Ibrahimi, A., Alaoui, S., Elkhadir, M., Harmouch, T., Mahmoud, M., Nejjari, C. and Benajah, D. (2016) Gastric Atrophy, Intestinal Metaplasia in Helicobacter pylori Gastritis: Prevalence and Predictors Factors. Journal of Biosciences and Medicines, 4, 43-49.

http://dx.doi.org/10.4236/jbm.2016.410005

Received: September 13, 2016

Accepted: October 16, 2016

Published: October 19, 2016

Copyright $\odot 2016$ by authors and Scientific Research Publishing Inc. This work is licensed under the Creative Commons Attribution International License (CC BY 4.0).

http://creativecommons.org/licenses/by/4.0/

\section{Abstract}

Gastric atrophy and intestinal metaplasia represent the most important premalignant lesions in gastric carcinogenesis. The severity of gastric mucosal inflammation depends on the bacterium Helicobacter pylori (HP), on the host and on environmental factors. The aim of our study is to determine the prevalence and factors associated with Gastric atrophy and intestinal metaplasia in patients infected with Helicobacter pylori. Methods: This is a prospective study over a period of 4 years (May 2009January 2015) conducted in the service of Hepatology and Gastroenterology in hospital university Hassan II of Fez in collaboration with microbiology and molecular biology laboratory and epidemiology service of Faculty of Medicine and Pharmacy Fes. We included in our study all patients aged over 15 years, having ulcerative dyspepsia, peptic ulcer disease, gastritis or esophagitis. Results: During the study period, 1190 patients were included of which $70 \%$ had HP infection $(\mathrm{N}=833)$. The average age was 48.21 years [16 - 99 years], sex ratio $\mathrm{M} / \mathrm{F}$ was $1,11.60 \%$ of patients were older than 45 years. Chronic smoking was found in $12 \%$ of patients. Gastric atrophy was observed in $84 \%(\mathrm{~N}=699)$ of patients infected with HP. Gastric atrophy was localized in $70 \%$ in the antrum and $30 \%$ in the fundus and $24 \%$ in both. The activity of gastritis $(\mathrm{p}=0.0001)$ and the density of the HP $(\mathrm{p}=0.005)$ were factors associated with atrophy. Intestinal metaplasia was observed in $13.5 \%$ of patients $(\mathrm{N}=112)$. The density of HP $(p=0.037)$ and severe atrophy $(p=0.001)$ were factors associated with 
metaplasia. Other factors studied: age, sex, smoking, $\mathrm{Cag} A^{+}$genotype were not associated with either gastric atrophy or intestinal metaplasia. Conclusion: In our study, the prevalence of atrophic gastritis and intestinal metaplasia in patients infected with Helicobacter pylori was $84 \%$ and $13.5 \%$ respectively, which was a high prevalence. The activity of gastritis, and density of HP were factors associated with atrophy. The density of HP and severe atrophy were factors associated with metaplasia.

\section{Keywords}

Gastric Atrophy, Intestinal Metaplasia, Helicobacter pylori, Gastritis

\section{Introduction}

Since 1994, the International Agency for Research on Cancer (IARC) classified H. pylo$r i$ infection as a type 1 carcinogen with a level of imputation for gastric cancer comparable to that of tobacco for lung cancer and Hepatitis $\mathrm{C}$ virus for hepatocellular carcinoma. Since then, many epidemiological studies have confirmed the impact of $H$. pylori in gastric carcinogenesis.

Gastric atrophy and intestinal metaplasia represent the most important premalignant lesions in gastric carcinogenesis. The severity of gastric mucosal inflammation depends on the bacterium Helicobacter pylori (HP), on the host and on environmental factors. The aim of our study is to determine the prevalence and factors associated with gastric atrophy and intestinal metaplasia in patients infected with Helicobacter pylori in a Moroccan population.

\section{Patients and Methods}

\subsection{Study Description}

This is a prospective randomized study over a period of 4 years (May 2009-January 2015) in the service of Hepatology and Gastroenterology in hospital university Hassan II of Fez in collaboration with microbiology and molecular laboratory and epidemiology service of Faculty of Medicine and Pharmacy Fes. The study comparing the efficacy and safety of sequential treatment with standard triple therapy. From this study we retrospectively studied gastric atrophy and intestinal metaplasia in patients infected with HP. Patients consent was obtained.

\subsection{Inclusion Criteria}

o Patients aged over 15 years;

o Presence of ulcer dyspepsia;

o Presence of a peptic ulcer;

o Presence of gastritis;

o Presence of esophagitis.

An upper endoscopy was performed in all patients, with five biopsies: two in the an- 
trum, one at the angulus and two in the fundus.

HP detection was done by histology and/or polymerase chain reaction (PCR).

\section{Results}

\subsection{Studied Population}

During the study period, 1190 patients were included of which $70 \%$ had HP infection $(\mathrm{N}=833)$. The average age was 48.21 years [ 16 - 99 years], sex ratio $M / F$ was 1.11 . Sixty percent of patients were older than 45 years. Chronic smoking was found in $12 \%$ of cases (Table 1).

An upper endoscopy was performed in all patients, it was normal in $5.4 \%$ of patients $(\mathrm{N}=45)$, was found a gastritis in $63.6 \%(\mathrm{~N}=530)$, was found a peptic ulcer disease in $31 \%(\mathrm{~N}=258)($ Table 1$)$.

\subsection{Prevalence and Topography of Gastric Atrophy in Patients with HP Positive}

Gastric atrophy was observed in $84 \%(\mathrm{~N}=699)$ of patients infected with HP it was mild in $62 \%$, moderate in $35 \%$ and severe in $3 \%$. Gastric atrophy was localized in $70 \%$ in the antrum and in $30 \%$ in the fundus and in $24 \%$ in both.

\subsection{Prevalence and Topography of Intestinal Metaplasia in Patients with HP Positive}

Intestinal metaplasia was observed in $13.5 \%$ of patients $(\mathrm{N}=112)$, it was located in $10 \%$ of cases and diffuse in $90 \%$.

\subsection{Factors Associated with Atrophy and Metaplasia in Gastritis HP}

As described in Table 2 the main factors associated with atrophy and metaplasia in gastritis HP follow:

Table 1. Patients' characteristics.

\begin{tabular}{ccc}
\hline & Number of patients & Percentage \\
\hline Total number of patients & 1190 & - \\
HP infection rate & 833 & $70 \%$ \\
Average age & 48.21 & - \\
Range of age: & & $40 \%$ \\
$<45$ years & 333 & $60 \%$ \\
$>45$ years & 500 & - \\
Sex-ratio & 1.11 & $12 \%$ \\
Tobacco & 100 & \\
Endoscopy: & & $5.4 \%$ \\
Normal & 45 & $63.6 \%$ \\
Gastritis & 530 & $31 \%$ \\
peptic ulcer & 258 & \\
\hline
\end{tabular}


Table 2. Factors associated with atrophy and metaplasia in gastritis HP.

\begin{tabular}{ccc}
\hline Factor & Gastric atrophy $(\mathrm{N}=699)$ & Intestinal Metaplasia $(\mathrm{N}=112)$ \\
\hline Age & $\mathrm{p}^{*}=0.8$ & $\mathrm{p}=0.9$ \\
Sex & $\mathrm{p}=0.75$ & $\mathrm{p}=0.86$ \\
Tobacco & $\mathrm{p}=0.96$ & $\mathrm{p}=1$ \\
Density of HP & $\mathrm{p}=0.005$ & $\mathrm{p}=0.037$ \\
Activité of gastritis & $\mathrm{p}=0.0001$ & $\mathrm{p}=0.01$ \\
CagA status & $\mathrm{p}=1.2$ & $\mathrm{p}=0.9$ \\
\hline
\end{tabular}

*The $\mathrm{p}$ value defines the correlation between the gastric atrophy and each of the listed factors as well as the correlation between those latter ones and the intestinal metaplasia.

\subsubsection{Age}

Gastric atrophy was observed in $82 \%$ of patients under 45 years and $91 \%$ of patients over 45 years of age $(\mathrm{p}=0.8)$.

Intestinal metaplasia was noted in $12 \%$ of patients under 45 years and $17 \%$ of patients over 45 years $(\mathrm{p}=0.9)$.

Age was not associated to the atrophy and métaplasia.

\subsubsection{Density of HP}

Intense density of HP was noted in $70 \%$ of patients with atrophy $(\mathrm{p}=0.005)$ and in $80 \%$ of patients with metaplasia $(\mathrm{p}=0.037)$.

\subsubsection{Activity of Gastritis}

Severe gastritis activity was noted in $87.3 \%$ of patients who have atrophy $(\mathrm{p}=0.0001)$ and in $80 \%$ of patients who have metaplasia $(\mathrm{p}=0.01)$.

\subsubsection{CagA Status}

In our study the CagA + status was not associated with either atrophy or intestinal metaplasia.

Fifty two percent of patients who present atrophy had CagA + status and $48 \%$ had CAG A- $(\mathrm{p}=1.2)$.

Fifty five percent of patients who present metaplasia had CagA + status and $44.5 \%$ had Cag $\mathrm{A}-(\mathrm{p}=0.9)$.

\subsubsection{Relationship between Atrophy and Metaplasia}

Occurrence métaplasie is more detected in patients with severe atrophy $83.5 \%$ of patients presenting metaplasia had severe atrophy $(\mathrm{p}=0.001)$.

\section{Discussion}

It's been 30 years since Correa proposed the cascade of histological events leading to the occurrence of gastric cancer [1]-[3].

Gastric cancer is the terminal stage of a process vary from chronic gastritis, gastric atrophy and intestinal metaplasia [4]-[8]. 


\subsection{Gatric Atrophy Evaluation}

Gastric atrophy is defined by a rarefaction of gastric glands. It can vary from mild atrophy with reduction less than a third of the volume of the glands to severe atrophy with two-thirds reduction in the volume of glands [4] [9]. The volume of the glands depends to the volume of the lamina propria wich can be enlarged particularly in concomitant inflammation by infiltration by lymphoplasmacytic element.

That is why in chronic active gastritis, the determination of gland volume is difficult and there is an overestimation of atrophy [4].

In our study the prevalence of atrophy is $84 \%$, which is a high prevalence, may be overestimated because of the presence of active gastritis.

\subsection{Topography of Gastric Atrophy}

The significance of gastric atrophy depends on its topography.

In HP infection the gastric atrophy has varying topographies it can be localized in the antrum and in this context it not considered pre-neoplastic lesion, if atrophy affects both the gastric antrum and the body in this case the atrophy causes hypochlorhydria and hypergastrinemia and constitutes a precancerous lesion [4].

In a large cohort study of 1436 Japanese patients followed for 7 years the existence of a pan gastric atrophy or predominant in the gastric body was important risk factor for gastric cancer as opposed to the isolated antral gastritis [4].

\subsection{Intestinal Metaplasia}

Intestinal metaplasia is characterized by replacement of the gastric mucosa by intestinal mucosa chronologically this lesion occurs later than gastric atrophy [4] [9].

Several epidemiological studies in China and Japan showed strong predictive value for cancer occurrence in patients with intestinal metaplasia, similar results were found in a population of western patients followed for 10 years, in this study $8.4 \%$ of patients with intestinal metaplasia developed cancer in 10 years [4].

\subsection{Interest of the Eradication of HP in Precancerous Lesions}

Looking for and systematic eradication of HP in gastric cancer prevention does not yet the subject of consensus [4].

Several studies have reported a regression of atrophy and metaplasia after eradication of HP [9]-[14], (Table 3).

\subsection{Predictors Factors of Atrophy and Metaplasia}

Several studies have examined the predictors factors of atrophy and metaplasia.

Age, smoking, history of smoking, alcohol and rurality are risk factors of gastric atrophy and intestinal metaplasia reported in some studies [5] [12] [15].

Others studies reported the male gender as a risk factor for gastric atrophy and intestinal metaplasia [16]-[20].

In our study the activity of gastritis and the density of the HP were factors associated 
Table 3. Effect of Helicobacter pylori eradication in atrophic gastritis and intestinal metaplasia in studies with $\geq 2.5$ a year follow-up [4].

\begin{tabular}{cccccc}
\hline Reference & Country & $\mathrm{n}$ & Year follow up & Gastric atrophy & Intestinal Metaplasia \\
\hline Annibale et al. & Italy & 40 & 32 & improved & improved \\
Ito et al. & Japan & 26 & 60 & improved & improved \\
Kokkola et al. & Finland & 22 & 30 & improved & improved \\
Leug et al. & China & 587 & 60 & Slowed & Slowed progression \\
\hline
\end{tabular}

with atrophy. The density of HP and severe atrophy were factors associated with metaplasia.

\section{Conclusions}

In our study, the prevalence of atrophic gastritis and intestinal metaplasia in patients infected with Helicobacter pylori is $84 \%$ and $13.5 \%$ respectively, which is a high prevalence may be overestimated by inflammation.

The activity of gastritis and the density of the HP were factors associated with atrophy. The density of HP and severe atrophy were factors associated with metaplasia.

Our study did not assess the evolution of atrophy and metaplasia after eradication of HP.

\section{References}

[1] Correa, P. (1992) Human Gastric Carcinogenesis: A Multistep and Multifactorial Process. First American Cancer Society Award Lecture on Cancer Epidemiology and Prevention. Cancer Research, 52, 6735-6740.

[2] Correa, P., Cuello, C., Duque, E., et al. (1976) Gastric Cancer in Columbia. III. Natural History of Precursor Lesions. Journal of the National Cancer Institute, 57, 1027-1035.

[3] Correa, P. (1988) A Human Model of Gastric Carcino Genesis. Cancer Research, 48, 13191326.

[4] Delchier, J.-C. (2004) Les lésions précancéreuses gastriques: Quelle prévention: Gastroentérol. Clin Bio.

[5] You, W.C., Zhang, L., Gail, M.H., Li, J.Y., Chang, Y.S., Blot, W.J., Zhao, C.L., Liu, W.D., Li, H.Q., Ma, J.L., Hu, Y.R., Bravo, J.C., Correa, P., Xu, G.W. and Fraumeni Jr., J.F. (1998) Precancerous Lesions in Two Counties of China with Contrasting Gastric Cancer Risk. International Journal of Epidemiology, 27, 945-948. http://dx.doi.org/10.1093/ije/27.6.945

[6] Kawaguchi, H., Haruma, K., Komoto, K., Yoshihara, M., Sumii, K. and Kajiyama, G. Helicobacter pylori Infection Is the Major Risk.

[7] Uemura, N., Okamoto, S. and Yamamoto, S. Helicobacter pylori Infection and the Development of Gastric Cancer. New England Journal of Medicine, 345, 784-789. http://dx.doi.org/10.1056/NEJMoa001999

[8] Uemura, N., Mukai, T. and Okamoto, S. (1997) Effect of Helicobacter pylori Eradication on Subsequent Development of Cancer after Endoscopic Resection of Early Gastric Cancer. Cancer Epidemiology, Biomarkers \& Prevention, 6, 639-642.

[9] Leung, W.K., Lin, S.-R., Ching, J.Y.L., To, K.-F., Ng, E.K.W., Chan, F.K.L., Lau, J.Y.W. and 
Sung, J.J.Y. (2001) Prospects for Intervention in Gastric Carcinogenesis: Reversibility of Gastric Atrophy and Intestinal Metaplasia. Gut, 49, 2-4.

http://dx.doi.org/10.1136/gut.49.1.2

[10] Walker, M. (2003) Is Intestinal Metaplasia of the Stomach Reversible? Gut, 52, 1-4. http://dx.doi.org/10.1136/gut.52.1.1

[11] Ito, M., Haruma, K., Kamada, T., Mihara, M., Kim, S., Kitadai, Y., Sumii, M., Tanaka, S., Yoshihara, M. and Chayama, K. (2002) Helicobacter pylori Eradication Therapy Improves Atrophic Gastritis and Intestinal Metaplasia: A 5-Year Prospective Study of Patients with Atrophic Gastritis Aliment. Pharmacology \& Therapeutics, 16, 1449-1456. http://dx.doi.org/10.1046/j.1365-2036.2002.01311.x

[12] Leung, W.K., Lin, S.-R., Ching, J.Y.L., To, K.-F., Ng, E.K.W., Chan, F.K.L., Lau, J.Y.W. and Sung, J.J.Y. (2004) Factors Predicting Progression of Gastric Intestinal Metaplasia: Results of a Randomised Trial on Helicobacter pylori Eradication. Gut, 53, 1244-1249. http://dx.doi.org/10.1136/gut.2003.034629

[13] Sung, J.J.Y., Lin, S.R. and Ching, J.Y.L. (2000) Atrophy and Intestinal Metaplasia One Year after Cure of $H$. pylori Infection: A Prospective Randomized Study. Gastroenterology, 119, 7-14. http://dx.doi.org/10.1053/gast.2000.8550

[14] Ohkusa, T., Fujiki, K. and Takashimizu, I. (2001) Improvement of Atrophic Gastritis and Intestinal Metaplasia in Patients in Whom Helicobacter pylori Was Eradicated. Annals of Internal Medicine, 134, 380-386. http://dx.doi.org/10.7326/0003-4819-134-5-200103060-00010

[15] Nakamura, M., Haruma, K. and Kamada, T. (2002) Cigarette Smoking Promotes Atrophic Gastritis in Helicobacter pylori-Positive Subjects. Digestive Diseases and Sciences, 47, 675681. http://dx.doi.org/10.1023/A:1017901110580

[16] Hackelsberger, A., Gunther, T. and Schultze, V. (1999) Role of Aging in the Expression of Helicobacter pylori Gastritis in the Antrum, Corpus, and Cardia. Scandinavian Journal of Gastroenterology, 34, 138-143. http://dx.doi.org/10.1080/00365529950172989

[17] Schubert, T.T., Schubert, A.B. and Ma, C.K. (1992) Symptoms, Gastritis, and Helicobacter pylori in Patients Referred for Endoscopy. Gastrointestinal Endoscopy, 38, 357-360. http://dx.doi.org/10.1016/S0016-5107(92)70432-5

[18] Chen, X.-Y., van der Hulst, R.W.M. and Shi, Y. (2001) Comparison of Precancerous Conditions: Atrophy and Intestinal Metaplasia in Helicobacter pylori Gastritis among Chinese and Dutch Patients. Journal of Clinical Pathology, 54, 367-370. http://dx.doi.org/10.1136/jcp.54.5.367

[19] The Eurohepygast Study Group (2002) Risk Factors for Atrophic Chronic Gastritis in a European Population: Results of the Eurohepygast Study. Gut, 50, 779-785. http://dx.doi.org/10.1136/gut.50.6.779

[20] Ren, Z., Pang, G., Batey, R. and Routley, D. (2000) Non-Urease Producing Helicobacter pylori in Chronic Gastritis. Australian \& New Zealand Journal of Medicine, 30, 578-584. http://dx.doi.org/10.1111/j.1445-5994.2000.tb00859.x 
Submit or recommend next manuscript to SCIRP and we will provide best service for you:

Accepting pre-submission inquiries through Email, Facebook, LinkedIn, Twitter, etc. A wide selection of journals (inclusive of 9 subjects, more than 200 journals)

Providing 24-hour high-quality service

User-friendly online submission system

Fair and swift peer-review system

Efficient typesetting and proofreading procedure

Display of the result of downloads and visits, as well as the number of cited articles

Maximum dissemination of your research work

Submit your manuscript at: http://papersubmission.scirp.org/

Or contact jbm@scirp.org 